\title{
Selección y Preparación del Material de Trasplante para la Producción Exitosa de Lúpulos en Florida ${ }^{1}$
}

\author{
Shinsuke Agehara, Aleyda Acosta-Rangel, Mariel Gallardo, y Gary Vallad ${ }^{2}$
}

Lúpulo (Humulus lupulus L.), un ingrediente esencial de la cerveza, tiene el potencial de desarrollarse como un cultivo alternativo viable en Florida. En 2019, Florida ocupó el cuarto lugar a nivel nacional en producción de cerveza artesanal, con 329 cervecerías que producen 42.6 millones de galones de cerveza y generan un impacto económico de más de \$3 mil millones (Brewers Association 2019). En nuestras encuestas, muchas cervecerías han expresado un gran interés en utilizar lúpulos cultivados localmente. Sin embargo, la producción de lúpulo no está exenta de riesgos. A nivel mundial, la producción de lúpulo está plagada de muchas enfermedades, la mayoría de las cuales se introdujeron inadvertidamente a través del movimiento de material vegetal contaminado. Los propósitos principales de este artículo son prevenir la introducción de estas enfermedades en el estado y brindar recomendaciones para seleccionar y preparar material de siembra para una producción exitosa de lúpulo en Florida. Este artículo es parte de una serie más grande que revisará los desafíos de la producción de lúpulo, basado en experiencias en nuestro campo de investigación en el UF/IFAS Gulf Coast Research and Education Center (UF/IFAS GCREC) en Balm, FL.

\section{Métodos de Propagación}

Los lúpulos son dioicos, lo que significa que tienen plantas masculinas y femeninas separadas. Solo las plantas de lúpulo femeninas producen estróbilos o conos, que se utilizan en la elaboración de cerveza. Debido a que las plantas varían en género cuando se propagan a partir de semillas, sólo se usa la propagación vegetativa (asexual) a través de rizomas, esquejes o cultivo de tejidos para la producción comercial de lúpulo. Aunque la propagación a través de rizomas y esquejes es relativamente fácil y económica, tiene un alto riesgo de contaminación. De hecho, muchos patógenos fúngicos, virales y viroides (pequeños $\mathrm{ARN}$ infecciosos sin recubrimiento proteico) se han propagado en todo el mundo a través de material de plantación contaminado. Entre estas enfermedades, las dos enfermedades fúngicas más comunes y económicamente importantes son el mildiú velloso, causado por el organismo similar al hongo Pseudoperonospora humuli (Gent, Johnson, et al. 2015), y el mildiú polvoso, causado por el hongo Podosphaera macularis (Gent, Nelson, et al. 2015). Los virus del lúpulo más extendidos y destructivos incluyen el virus del mosaico del manzano (ApMV), el virus del mosaico del lúpulo (HpMV)

1. This document is HS1381s, one of a series of the Horticultural Sciences Department, UF/IFAS Extension. Original publication date May 2021. Visit the EDIS website at https://edis.ifas.ufl.edu for the currently supported version of this publication.

2. Shinsuke Agehara, assistant professor, Horticultural Sciences Department; Aleyda Acosta-Rangel, former postdoctoral associate, Horticultural Sciences Department; Mariel Gallardo, graduate research assistant, Horticultural Sciences Department; and Gary Vallad, professor, Plant Pathology Department; UF/IFAS Gulf Coast Research and Education Center, Balm, 33598. Translated by Mariel Gallardo.

El uso de nombres comerciales citados en esta publicación es sólo con el propósito de brindar información específica. El Instituto (UF/IFAS) no garantiza los productos nombrados, y las referencias a ellos en esta publicación no significan nuestra aprobación a la exclusión de otros productos de composición comparable.

Use pesticidas con cuidado. Lea y siga las instrucciones en la etiqueta del fabricante.

The Institute of Food and Agricultural Sciences (IFAS) is an Equal Opportunity Institution authorized to provide research, educational information and other services

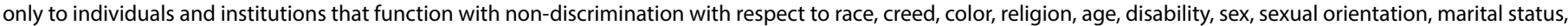
national origin, political opinions or affiliations. For more information on obtaining other UF/IFAS Extension publications, contact your county's UF/IFAS Extension office. U.S. Department of Agriculture, UF/IFAS Extension Service, University of Florida, IFAS, Florida A \& M University Cooperative Extension Program, and Boards of County Commissioners Cooperating. Nick T. Place, dean for UF/IFAS Extension. 
y el virus latente del lúpulo (HpLV) (Eastwell y Barbara 2015a; Eastwell y Barbara 2015b). También se ha reportado en los Estados Unidos una pérdida significativa de rendimiento causada por dos viroides, el viroide latente del lúpulo y el viroide del enanismo del lúpulo (Eastwell 2015; Eastwell y Barbara 2015c). A pesar de los esfuerzos globales para desarrollar un programa de plantas limpias basado en plantas propagadas por cultivo de tejidos, muchos de estos patógenos ahora son endémicos de la mayoría de las áreas de producción de lúpulo fuera de Florida.

Hasta la fecha, Florida no tiene problemas de producción a causa de patógenos típicamente asociados con la producción de lúpulo en todo el mundo. Para evitar la posibilidad de introducir estos patógenos en el estado, se recomienda encarecidamente a los productores de Florida que utilicen plántulas propagadas por cultivo de tejidos que estén certificadas libres de virus. No recomendamos el uso de rizomas y esquejes debido a la alta probabilidad de infección. Una vez que las plantas infectadas se introducen en un campo de lúpulo, los patógenos se propagarán a otras plantas a través de la producción de esporas (mildiú velloso y mildiú polvoso) o transmisión mecánica (virus y viroides). Aunque existen fungicidas efectivos para el mildiú velloso y el mildiú polvoso, dadas las condiciones climáticas de Florida, el manejo químico de estas enfermedades podría no ser económicamente viable. Para los virus y viroides, no existen opciones de pesticidas efectivas, por tal motivo, prevenir su entrada y erradicar las plantas infectadas son las únicas opciones de manejo disponibles para los productores de Florida.

\section{Cultivo de Tejidos}

El cultivo de tejidos es un conjunto de técnicas que implican el uso de pequeños trozos de tejido vegetal que son cultivados en un medio nutritivo en condiciones estériles (George et al. 2008). El cultivo de tejidos se puede utilizar como método de propagación y eliminación de enfermedades. El cultivo de la punta de micro brotes (microshoot tip), a menudo combinado con terapia de calor o quimioterapia, puede eliminar infecciones virales y de otro tipo, y producir material vegetal limpio para trasplante. En la industria de la horticultura, el cultivo de tejidos se utiliza a menudo para la producción comercial de plantas libres de virus.

El Clean Plant Center Northwest (http://cpcnw.wsu.edu/) es miembro de la National Clean Plant Network para Lúpulos (http://nationalcleanplantnetwork.org/HOPS_CPN/), el cual tiene sede en el Washington State University Irrigated Agriculture Research and Extension Center en Prosser,
Washington. El Clean Plant Center Northwest utiliza técnicas de cultivo de tejidos para proporcionar material para trasplante limpio y libre de virus y viroides conocidos del lúpulo. Para asegurarse de comenzar con material vegetal limpio, puede comprar material de siembra de la National Clean Plant Network y propagarlo usted mismo. Algunos viveros comerciales ubicados en Florida pueden ayudar en la propagación. Las plántulas propagadas por cultivo de tejidos también se pueden comprar en viveros comerciales (consulte la sección "Tiempo y Material de Trasplante" para obtener más detalles).

\section{Rizomas}

Un rizoma es un tallo subterráneo modificado que puede desarrollar nuevos brotes y raíces a partir de sus nudos. Aunque los rizomas se utilizan como material de propagación común en los principales estados productores de lúpulo, no recomendamos el uso de rizomas porque tienen una alta probabilidad de infectarse con patógenos fúngicos o virales. De hecho, se diagnosticó que algunos rizomas comprados en viveros comerciales y plantados en UF/ IFAS GCREC estaban infectados con el virus del mosaico del manzano, el virus del mosaico del lúpulo y el virus latente del lúpulo poco después de la siembra. Al final de la temporada, retiramos todas las plantas y fumigamos todo el campo. Desde el restablecimiento del campo de lúpulo de GCREC en 2017 con plántulas propagadas por cultivo de tejidos, no hemos experimentado problemas graves causados por enfermedades.

\section{Semillas}

Las semillas no deben usarse para la propagación del lúpulo porque las plantas que crecen a partir de semillas varían en género. Las plantas masculinas no son deseables para los cultivadores comerciales de lúpulo, no solo porque no producen conos, sino también porque las plantas femeninas podrían polinizarse y producir semillas en conos. Un alto nivel de ácidos grasos en las semillas puede afectar negativamente el perfil de sabor y la estabilidad de la cerveza (Neve 1991). En las principales áreas productoras de lúpulo, se han realizado enormes esfuerzos para eliminar las plantas masculinas cerca de los campos comerciales de lúpulo. Sin embargo, las plantas masculinas son esenciales en los programas de mejoramiento de lúpulo para desarrollar nuevos cultivares. 


\section{Preparación de Plántulas} Propagadas por Cultivo de Tejidos para ser Trasplantadas en el

\section{Campo}

\section{Tiempo y Material de Trasplante}

Recomendamos plantar lúpulos a principios de la primavera, después de que haya pasado el peligro de las heladas. En el centro de Florida, por ejemplo, el momento óptimo para plantar es desde mediados de febrero hasta principios de marzo.

Las plántulas de lúpulo propagadas por cultivo de tejidos se pueden comprar en viveros comerciales en los principales estados productores de lúpulo como Washington, Oregon, Michigan y Nueva York, las plántulas normalmente están disponibles solo después de principios de abril, dado a que es el comienzo de la temporada de siembra en dichos estados. Para plantar en el momento óptimo en Florida, puede usar plántulas propagadas localmente. Al obtener plántulas propagadas por cultivo de tejidos producidas en Florida se reduce la probabilidad de introducir patógenos que causan mildiú velloso o mildiú polvoso, ninguno de ellos ha sido reportado en el estado.

Actualmente, solo un vivero (Agri-Starts, Apopka, FL) suministra plántulas de lúpulo propagadas por cultivo de tejidos en Florida. Verifique la disponibilidad y el tamaño de las plántulas con anticipación. Es posible que sea necesario trasplantar y cultivar pequeñas plántulas en macetas hasta que alcancen un tamaño adecuado para plantar en el campo. Este proceso puede tardar de 4 a 6 semanas, según el tamaño de las plántulas y las condiciones de crecimiento. La Figura 1 muestra las plántulas de lúpulo 'Cascade' entregadas por el vivero mencionado, y la Figura 2 muestra una plántula madura lista para el campo. Para un experimento de campo establecido en UF/IFAS GCREC en 2020, trasplantamos plántulas en macetas pequeñas a mediados de enero y los mantuvimos en nuestro invernadero durante aproximadamente 5 semanas antes de plantarlos en el campo.

\section{Macetas}

Elegir el tamaño de maceta correcto es fundamental no sólo para cultivar plantas saludables, sino también para ahorrar costos. En macetas que son demasiado pequeñas, el sustrato para macetas se seca tan rápido que será difícil mantener la humedad y la salinidad en un nivel óptimo. Las plantas también podrían enredarse rápidamente, lo que puede afectar negativamente el desarrollo y establecimiento de las raíces en el campo. Si las macetas son demasiado grandes, por el contrario, el sustrato para macetas se seca muy lentamente, lo que hace que las plantas sean más vulnerables a las enfermedades de pudrición de la raíz causadas por especies oportunistas de Pythium y Fusarium. Las macetas más grandes también requieren más costos de materiales (por ejemplo, macetas, medios de cultivo, agua, fertilizantes), espacio de invernadero y mano de obra por planta.

El tamaño ideal de la maceta se puede determinar en función del tamaño inicial de las plántulas y el tamaño deseado de las plántulas para trasplantar en campo. Para las plántulas que se muestran en la Figura 1, el tamaño de la maceta que recomendamos es de 4 pulgadas de diámetro. El uso de bandejas para macetas puede evitar que las macetas se vuelquen, facilitar el espaciado y el transporte eficiente de las macetas. La aplicación de pesticidas y el tutorado de los tallos se pueden realizar de manera más eficiente cuando las macetas están espaciadas uniformemente y aseguradas en bandejas.

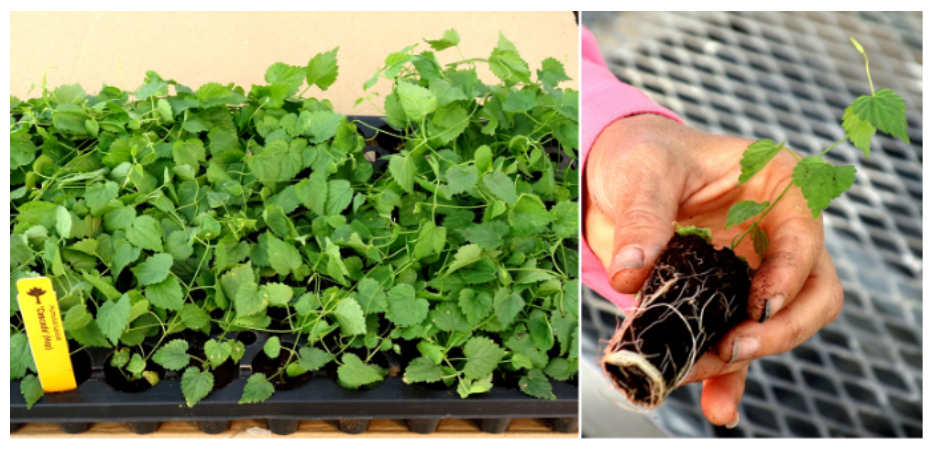

Figura 1. Plántulas propagadas por cultivo de tejidos de lúpulo 'Cascade.' Estas plántulas deben trasplantarse y mantenerse en macetas hasta que alcancen un tamaño adecuado para el campo. Créditos: Shinsuke Agehara, UF/IFAS

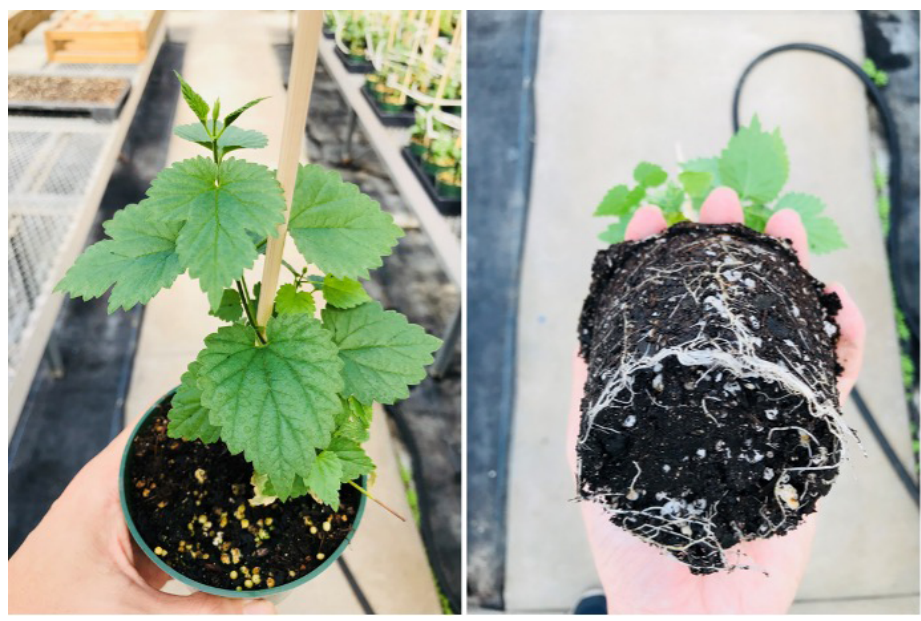

Figura 2. Una plántula de lúpulo 'Cascade' propagada por cultivo de tejidos y lista para el campo.

Créditos: Shinsuke Agehara, UF/IFAS 


\section{Sustrato para Macetas}

Los sustratos para macetas utilizados en la industria de los invernaderos contienen una variedad de materiales "libres de suelo", cómo turba, vermiculita, perlita, fibra de coco y corteza compostada. Estos materiales son ideales para cultivar plantas en macetas porque son livianos y brindan alta capacidad de retención de agua, aireación y drenaje.

Hay muchos sustratos comerciales para macetas, que contienen mezclas para diferentes usos, como por ejemplo propagación, para cultivos específicos, o para fines generales. Para el cultivo de plántulas de lúpulo en macetas de 4 pulgadas, recomendamos sustratos para macetas de uso general que sean de baja densidad con alto drenaje y alta aireación. El sustrato que usamos está compuesto de turba del género sphagnum, corteza de pino fina y envejecida, perlita y vermiculita, y tiene una densidad de 14 a 16 libras por pie cúbico. Agregamos perlita adicional a esta mezcla para macetas en una proporción de 1: 9 para mejorar la aireación y el drenaje. Es fundamental no comprimir el sustrato al llenar las macetas. De lo contrario, las propiedades de aireación y drenaje se verán comprometidas, lo que puede propiciar las enfermedades de la pudrición de la raíz.

\section{Riego}

La frecuencia y la cantidad de riego deben determinarse en función del tamaño de la maceta, la capacidad de retención de agua del sustrato para macetas, el consumo de la planta, la humedad y aireación óptimas para su cultivo y las condiciones ambientales. La regla general para el riego en invernaderos es mantener la humedad del sustrato por encima del $50 \%$ de la capacidad de retención de agua (Merhaut 2014). Es importante permitir que el sustrato se seque entre los ciclos de riego para mantener un drenaje adecuado y prevenir enfermedades de las raíces. De igual modo, se debe tener cuidado de no secar demasiado el sustrato. De lo contrario, la rehumectación uniforme de la turba será muy difícil. También debe evitarse el exceso de agua que conduce a una mala aireación y a la lixiviación de nutrientes. Para obtener más información técnica sobre el riego en invernadero, consulte https://edis.ifas.ufl.edu/ cv264 (Hochmuth 2015).

La Figura 3 muestra el sistema de riego utilizado para cultivar plántulas de lúpulo en nuestro invernadero.

Se conectaron ocho goteros en ángulo a un emisor de compensación de presión de 2 galones por hora utilizando dos divisores de emisor de 4 terminales. Se utilizó un gotero por maceta, proporcionando $16 \mathrm{ml}(0,54 \mathrm{fl} \mathrm{oz})$ de agua por minuto. Nuestro programa de riego inicial fue de un ciclo de tres minutos cada dos días, pero se incrementó a un ciclo de cinco minutos por día hasta que las plántulas alcanzaran el tamaño óptimo para el campo.

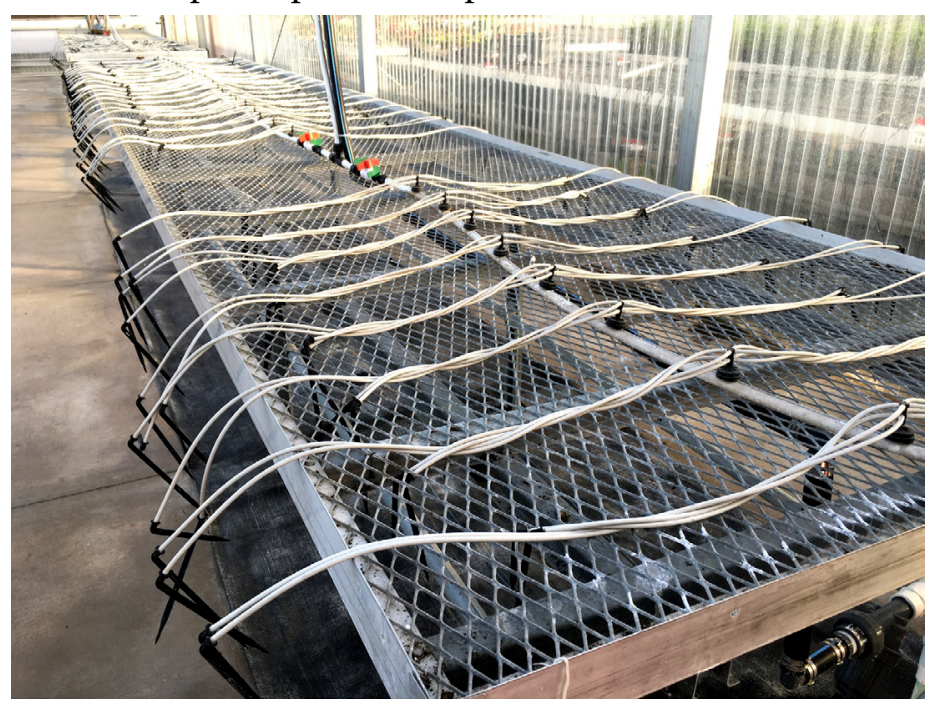

Figura 3. El sistema de riego por goteo utilizado para cultivar plántulas de lúpulo en UF/IFAS GCREC en Balm, FL. Se conectaron ocho goteros en ángulo a un emisor de compensación de presión de 2 galones por hora utilizando dos divisores de emisor de 4 terminales.

Créditos: Shinsuke Agehara, UF/IFAS

\section{Fertilización}

La mayoría de los sustratos para macetas contienen cantidades insuficientes de nutrientes y no mantendrán el crecimiento de las plantas sin una aplicación adicional de fertilizantes. En la producción en invernadero de plantas cultivadas en contenedores, los nutrientes generalmente se administran utilizando fertilizantes solubles en agua con el riego (fertirrigación) o mediante la aplicación granular de fertilizantes de liberación controlada. La fertirrigación proporciona flexibilidad para cambiar las formulaciones de fertilizantes y las tasas de aplicación, mientras que los principales beneficios del uso de fertilizantes de liberación controlada son la facilidad de uso y la posible reducción de la lixiviación de nutrientes. Ambos métodos de fertilización se pueden utilizar para cultivar plántulas de lúpulo en un invernadero. Los criterios para elegir una u otra incluyen la cantidad de plantas a cultivar, la mano de obra y el equipo disponible.

Los fertilizantes están disponibles en muchas formulaciones diferentes. Es importante elegir una formulación que coincida con los requerimientos nutricionales de la planta. Los rangos óptimos de concentración de nutrientes en los pecíolos del lúpulo son $3.2 \%-5.6 \%, 0.27 \%-0.54 \%$ y $1.6 \%-3.4 \%$, para nitrógeno, fósforo y potasio, respectivamente (Sirrine 2019). El análisis de tejidos de nuestras muestras de hojas también mostró rangos de concentración de nutrientes similares. Por lo tanto, recomendamos una 
formulación que sea relativamente alta en nitrógeno y baja en fósforo (por ejemplo, 15-9-12). También es importante elegir un fertilizante que contenga micronutrientes. En nuestro invernadero, el hierro es la deficiencia de micronutrientes más observada (Figura 4).

En nuestro programa de fertilización, usamos un fertilizante de liberación controlada (Osmocot Plus, 15-9-12, liberación de 3 a 4 meses) y lo aplicamos en cada maceta, sobre el sustrato. La duración estándar de liberación de nutrientes de este fertilizante es de 3 a 4 meses, aunque varía según la temperatura y la humedad (por ejemplo, 3 a 4 meses a $70^{\circ} \mathrm{F}$ y 2 a 3 meses a $80^{\circ} \mathrm{F}$ ). Contiene nitrógeno (15\%), fósforo (9\%), potasio (12\%), magnesio (1.3\%), azufre (5.9\%) y seis micronutrientes. Inmediatamente después del trasplante, se roció una cucharadita de este fertilizante (alrededor de 2 gramos) sobre la superficie del sustrato en cada maceta, evitando el contacto directo con los tallos. También utilizamos un fertilizante de micronutrientes (Microplex) para suministrar micronutrientes adicionales mediante fertirrigación. Este fertilizante es soluble en agua y contiene altas concentraciones de cobre (1.5\%), hierro (4\%), manganeso (4\%) y zinc (1.5\%). La solución nutritiva que contenía 2.5 gramos del fertilizante por litro ( $0.33 \mathrm{oz}$ por galón) se aplicó a $50 \mathrm{~mL}$ ( $1.7 \mathrm{floz}$ ) por maceta semanalmente comenzando una semana después del trasplante en macetas.
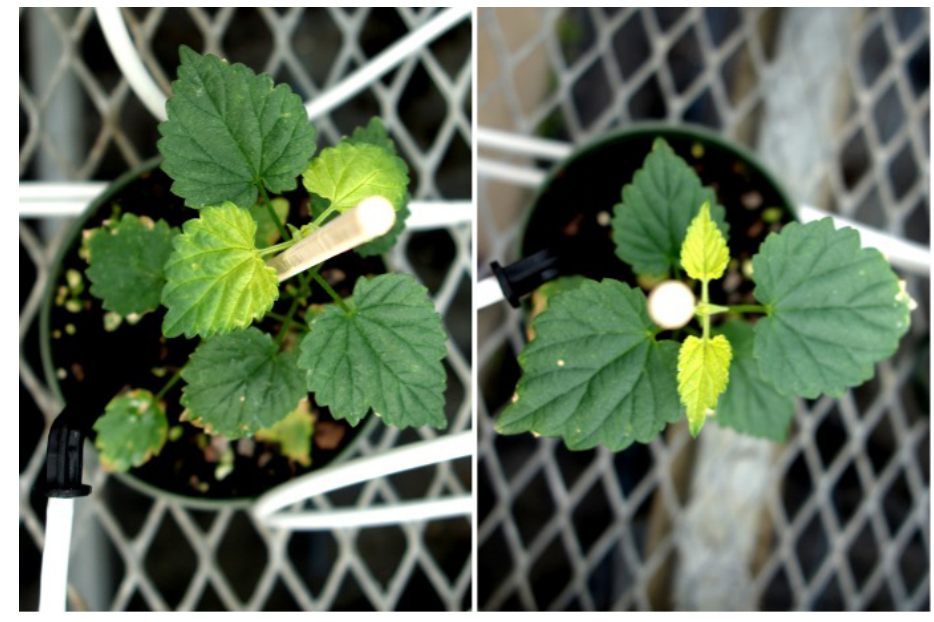

Figura 4. Plántulas de lúpulo 'Cascade' con síntomas de deficiencia de hierro. Los síntomas aparecen en las hojas nuevas. El síntoma más común es la clorosis intervenal, la hoja se torna amarilla y las venas permanecen verdes. En casos severos, las hojas nuevas permanecerán pequeñas y se volverán casi blancas, y las puntas de crecimiento pueden comenzar a morir.

Créditos: Shinsuke Agehara, UF/IFAS GCREC

\section{Tutorado}

Las plantas de lúpulo tienden a crecer verticalmente por el desarrollo de tallos que se entrelazan y suben por el soporte que tengan disponible. Es necesario un sistema de soporte, no solo para promover el crecimiento vertical de los tallos sino también para evitar que las plantas se enreden entre sí en un invernadero. Usamos una brocheta de bambú (17.3 pulgadas de largo y 0.2 pulgadas de grosor) como soporte en cada maceta (Figuras 2 y 4 ). Esta brocheta de bambú es ideal para tutorar tallos de lúpulo en una maceta pequeña porque es lo suficientemente liviana para ser sostenida por la maceta y su superficie rugosa es adecuada para que los tallos suban. Los lúpulos trepan en sentido horario, por lo que es importante entrenarlos siguiendo esta tendencia natural. Los tallos deben tutorarse una vez por semana inicialmente, luego dos veces por semana cuando comienzan a crecer rápidamente.

\section{Control de Enfermedades}

Las pudriciones de las raíces comúnmente asociadas con especies oportunistas de Pythium y Fusarium pueden ser un problema en los invernaderos. Sin embargo, en nuestra experiencia, la mayoría de estos problemas están asociados con las plantas que se riegan en exceso, se fertilizan en exceso (lo que genera un alto contenido de sales) y raíces enredadas. Las prácticas culturales discutidas en las secciones anteriores (fertilización, riego, sustratos para macetas y selección de macetas adecuadas) pueden ayudar a evitar complicaciones de estas enfermedades. El uso de fungicidas preventivos (Tabla 1) puede ayudar a tratar las plántulas afectadas, pero los usuarios siempre deben tratar primero de abordar cualquier causa subyacente relacionada al manejo del cultivo.

\section{Control de Plagas}

Las plagas comunes del lúpulo observadas en los invernaderos del UF/IFAS GCREC incluyen ácaros, trips y pulgones. Entre estas plagas, la arañita roja, incluido el ácaro de dos puntos (Tetranychus urticae) y la araña roja (Tetranychus urticae), se establecen de forma rutinaria en las plántulas de lúpulo y pueden causar daños importantes si no son controladas. Aunque existen opciones químicas para el control de ácaros (por ejemplo, abamectina, acequinocilo, etoxazol, fenazaquin, hexitiazox), los mejores resultados en el manejo de ácaros se han obtenido mediante la aplicación de un depredador comercial de ácaros, Phytoseiulus persimilis.

\section{Sanitización}

La sanitización es otra práctica cultural importante para cualquier planta producida en invernadero. Asegurar que todas las macetas estén limpias de restos de plantas de usos anteriores es extremadamente importante, especialmente porque muchos patógenos virales y viroides pueden transmitirse mecánicamente. El saneamiento también es 
importante para minimizar cualquier problema con patógenos oportunistas comunes, como Botrytis, Alternaria, Fusarium y Pythium. Siempre es ideal lavar las superficies, el equipo y las herramientas del invernadero que se utilizan para podar las plantas con un desinfectante aprobado, cómo hipoclorito de sodio doméstico (solución al 10\%), etanol (solución al 70\%), amonio cuaternario (por ejemplo, Green Shield, Physan 20), dióxido de hidrógeno (p. ej., OxiDate, ZeroTol) y otros desinfectantes multipropósito como Virkon. Tenga cuidado al preparar y utilizar estos productos de limpieza: hipoclorito de sodio es muy volátil y fitotóxica, y el etanol es inflamable. Para obtener una lista completa de productos de limpieza, consulte https://www. fdacs.gov/content/download/9901/file/decontamination. pdf (Florida Department of Agriculture and Consumer Services 2017). Estos productos están aprobados por el Citrus Health Response Program, pero también deberían ser eficaces contra muchos agentes infecciosos del lúpulo.

\section{Trasplante}

Una plántula de lúpulo del tamaño ideal para su trasplante en el campo debe tener un sistema de raíces sano y robusto expandido en toda la maceta (Figura 2), de modo que pueda sacarse fácilmente sin dañar las raíces. Recomendamos plantar dos plántulas por hoyo de plantación. Si las plántulas están unidas a las raíces en macetas, desenrede las raíces con los dedos antes de plantar. Haga un hoyo de plantación lo suficientemente ancho y profundo para insertar todo el sistema de raíces y cubra la superficie del sustrato con 0.25 a 0.5 pulgadas de tierra. Finalmente, aplique la corteza fina de pino alrededor de las plantas para cubrir el suelo, minimizar la evaporación y suprimir el crecimiento de malezas. La Figura 5 muestra plántulas de lúpulo 14 días después del trasplante en el campo de lúpulo UF/IFAS GCREC. Las plantas deben regarse inmediatamente después de la siembra. El fertilizante de liberación controlada aplicado en el invernadero debería continuar aportando nutrientes por un tiempo, pero recomendamos comenzar la fertirrigación dentro de una semana después de la siembra para estimular el crecimiento de nuevas raíces en el suelo del campo. Para la preparación de campo, consulte https://edis.ifas.ufl.edu/ hs1354 (Agehara et al. 2020).

\section{Diagnóstico de Plantas}

Independientemente de dónde se obtengan los materiales de las plantas de lúpulo, es vital hacer que las plantas se evalúen para garantizar que estén libres de patógenos virales y viroides. Los proveedores externos como Agdia pueden proporcionar una variedad de servicios de prueba para el lúpulo (https://www.agdia.com/testing-services/ hops). Como se mencionó anteriormente, la obtención de plantas propagadas por cultivo de tejidos del Clean Plant Center Northwest puede asegurar que el material de plantación esté libre de virus y viroides. Actualmente, AgriStarts es el único vivero con sede en Florida que suministra plántulas de lúpulo propagadas por cultivo de tejidos.

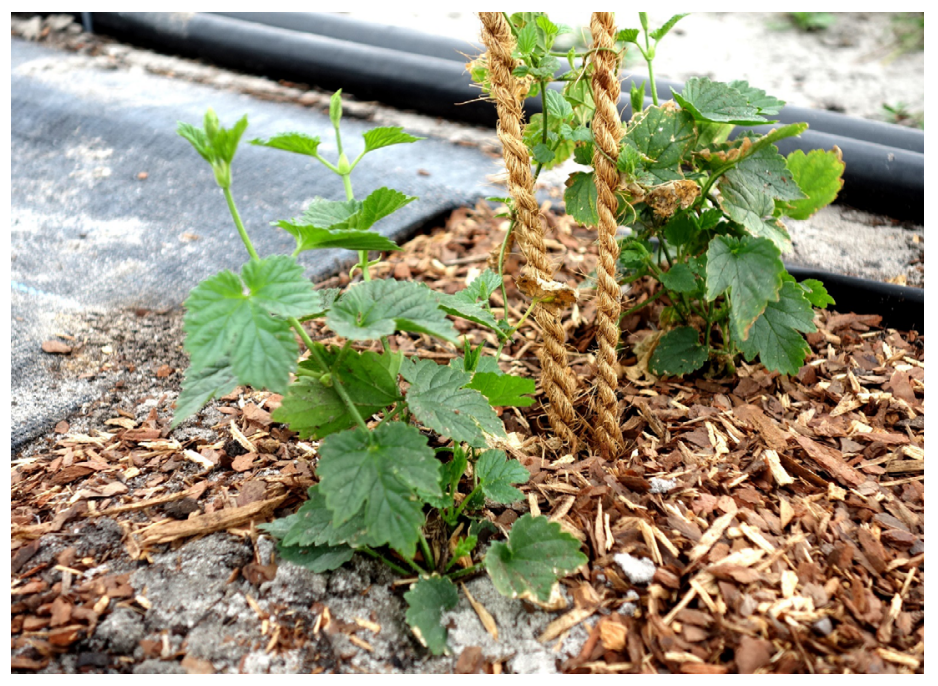

Figura 5. Plántulas de lúpulo 'Cascade' 14 días después del trasplante en el campo de investigación de lúpulo UF/IFAS GCREC en Balm, FL. Créditos: Shinsuke Agehara, UF/IFAS

\section{Literatura Citada}

Agehara, S., A. Acosta-Rangel, Z. Deng, J. Rechcigl, and S. Bollin. 2020. "Hop Yard Establishment and Trellis Construction in Florida.” EDIS 2020 (1). https://doi. org/10.32473/edis-hs1354-2020

Brewers Association. 2019. "Florida's Craft Beer Sales and Production Statistics, 2018." Accessed Apr. 28, 2020. https://www.brewersassociation.org/statistics-and-data/ state-craft-beer-stats $/$ ?state $=\mathrm{FL}$

Eastwell, K. C. 2015. "Hop Stunt Viroid." In Field Guide for Integrated Pest Management in Hops, 3rd Ed., edited by S. D. O'Neal, D. B. Walsh, and D. H. Gent. Yakima, WA: US Hop Industry Plant Protection Committee.

Eastwell, K. C., and D. J. Barbara. 2015a. "Apple Mosaic Virus." In Field Guide for Integrated Pest Management in Hops, 3rd Ed., edited by S. D. O’Neal, D. B. Walsh, and D. H. Gent. Yakima, WA: US Hop Industry Plant Protection Committee.

Eastwell, K. C., and D.J. Barbara. 2015b. "Carlavirus Complex: American Hop Latent Virus, Hop Latent Virus, and Hop Mosaic Virus." In Field Guide for Integrated Pest Management in Hops, 3rd Ed., edited by S. D. O’Neal, D. B. Walsh, and D. H. Gent. Yakima, WA: US Hop Industry Plant Protection Committee. 
Eastwell, K. C., and D. J. Barbara. 2015c. "Other Viruses, Viroids, and Virus-like Agents." In Field Guide for Integrated Pest Management in Hops, 3rd Ed., edited by S. D. O'Neal, D. B. Walsh, and D. H. Gent. Yakima, WA: US Hop Industry Plant Protection Committee.

Florida Department of Agriculture and Consumer Services. 2017. "Approved Decontamination Products \& Methods." Accessed Apr. 28, 2020. https://www.fdacs.gov/content/ download/9901/file/decontamination.pdf

Gent, D. H., D. A. Johnson, A. J. Gevens, and M. K. Hausbeck. 2015. "Downy Mildew." In Field Guide for Integrated Pest Management in Hops, 3rd Ed., edited by S. D. O’Neal, D. B. Walsh, and D. H. Gent. Yakima, WA: US Hop Industry Plant Protection Committee.

Gent, D. H., M. E. Nelson, D. M. Gadoury, A. J. Gevens, and M. K. Hausbeck. 2015. "Powdery Mildew." In Field Guide for Integrated Pest Management in Hops, 3rd Ed., edited by S. D. O’Neal, D. B. Walsh, and D. H. Gent. Yakima, WA: US Hop Industry Plant Protection Committee.

George, E. F., M. A. Hall, and G. De Klerk. 2008. Plant Propagation by Tissue Culture. 3rd Ed. Dordrecht, The Netherlands: Springer.

Hochmuth, G. 2015. "Irrigation of Greenhouse Vegetables-Florida Greenhouse Vegetable Production Handbook, Vol 3."EDIS2018 (6). https://edis.ifas.ufl.edu/cv264

Merhaut, D. 2014. "Get Cultured: Managing Media to Optimize Water Use.” UCNFA News. 18 (2): 13-15.

Neve, R. A. 1991. Hops. Berlin: Springer Science \& Business Media.

Sirrine, R. 2019. "Recommended Nutrient

Ranges for Hop Petiole Samples." Accessed Apr. 28, 2020. https://www.usahops.org/growers/ recommended-nutrient-ranges-for-hop-peti 
TABLA 1. Fungicidas preventivos etiquetados para el manejo de patógenos comunes del suelo (Pythium, Phytophthora, Rhizoctonia y Fusarium spp.) que causan pudrición de la raíz en lúpulos, lúpulos en macetas y plantas de lúpulo de campo.

\begin{tabular}{|c|c|c|c|c|}
\hline $\begin{array}{l}\text { Fungicida } \\
\text { (ingredient activo) }\end{array}$ & $\begin{array}{l}\text { Código } \\
\text { FRAC }^{1}\end{array}$ & $\begin{array}{l}\text { Acceso } \\
\text { restringido }\end{array}$ & OMRI & Notas $^{2}$ \\
\hline $\begin{array}{l}\text { Brandt Organics Aleo } \\
\text { (acaite de ajo) }\end{array}$ & $\mathrm{NC}$ & $0 \mathrm{hr}$ & SI & $\begin{array}{l}\text { Puede aplicarse al follaje; no aplique cuando las plantas estén estresadas o la } \\
\text { temperatura del aire sea }>90^{\circ} \mathrm{F} \text {. Si se aplica a plántulas o plantas pequeñas en } \\
\text { macetas, use las dosis descritas para cultivos ornamentales. Leer etiqueta. }\end{array}$ \\
\hline $\begin{array}{l}\text { Confine } \\
\text { (acido fosfórico, sales de } \\
\text { mono y dipotasio) }\end{array}$ & 33 & $4 \mathrm{hr}$ & NO & Se puede aplicar al follaje, en drench o mediante riego. Leer etiqueta. \\
\hline $\begin{array}{l}\text { Custos } \\
\text { (aceite de ajo, excipiente, } \\
\text { aceite de romero y menta) }\end{array}$ & NC & 0 & SI & $\begin{array}{l}\text { Puede aplicarse al follaje; no aplique cuando las plantas estén estresadas o la } \\
\text { temperatura del aire sea }>90^{\circ} \mathrm{F} \text {. Leer etiqueta. }\end{array}$ \\
\hline $\begin{array}{l}\text { K-Phite 7LP } \\
\text { (acido fosfórico, sales de } \\
\text { mono y dipotasio) }\end{array}$ & 33 & $4 \mathrm{hr}$ & NO & Se puede aplicar al follaje, en drench o mediante riego.Leerr etiqueta. \\
\hline $\begin{array}{l}\text { Pvent } \\
\text { (Gliocladium catenulatum } \\
\text { cepa J1446) }\end{array}$ & NC & $4 \mathrm{hr}$ & SI & $\begin{array}{l}\text { Se puede aplicar al follaje, como drench, mediante riego o incorporarse en } \\
\text { sustratos para macetas. Leeretiqueta. }\end{array}$ \\
\hline $\begin{array}{l}\text { Rampart } \\
\text { (acido fosfórico, sales de } \\
\text { mono y dipotasio) }\end{array}$ & 33 & $4 \mathrm{hr}$ & NO & Puede aplicarse sobre follaje o mediante riego. Leer etiqueta. \\
\hline $\begin{array}{l}\text { Resist } 57 \\
\text { (acido fosfórico, sales de } \\
\text { mono y dipotasio) }\end{array}$ & 33 & $4 \mathrm{hr}$ & NO & Puede aplicarse sobre follaje o mediante riego. Leer etiqueta. \\
\hline $\begin{array}{l}\text { SaniDate } 12.0 \\
\text { (peróxido de hidrógeno, } \\
\text { ácido peroxiacético) }\end{array}$ & NC & $0 \mathrm{hr}$ & NO & $\begin{array}{l}\text { Se puede aplicar al follaje, al drench, mediante riego o como inmersión antes } \\
\text { de plantar. Consulte la etiqueta para obtener instrucciones de aplicación } \\
\text { específicas. }\end{array}$ \\
\hline $\begin{array}{l}\text { Serenade ASO } \\
\text { (Bacillus subtilis cepa QST } \\
\text { 713) }\end{array}$ & 44 & $4 \mathrm{hr}$ & SI & $\begin{array}{l}\text { Puede aplicarse al suelo para atacar patógenos transmitidos por el suelo. } \\
\text { Leer etiqueta. }\end{array}$ \\
\hline $\begin{array}{l}\text { SporeQuell } 15 \% \\
\text { (peróxido de hidrógeno, } \\
\text { ácido peroxiacético) }\end{array}$ & $\mathrm{NC}$ & $0 \mathrm{hr}$ & NO & $\begin{array}{l}\text { Se puede aplicar al follaje, como drench, mediante riego o como inmersión } \\
\text { antes de plantar. Consulte la etiqueta para obtener instrucciones de } \\
\text { aplicación específicas. }\end{array}$ \\
\hline $\begin{array}{l}\text { TerraClean } 5.0 \\
\text { (peróxido de hidrógeno, } \\
\text { ácido peroxiacético) }\end{array}$ & $\mathrm{NC}$ & $0 \mathrm{hr}$ & NO & $\begin{array}{l}\text { Se puede aplicar al follaje, como drench, mediante riego o como inmersión } \\
\text { antes de plantar. Consulte la etiqueta para obtener instrucciones de } \\
\text { aplicación específicas. }\end{array}$ \\
\hline $\begin{array}{l}\text { Veg'lys } \\
\text { (aceite de ajo) }\end{array}$ & $\mathrm{NC}$ & $0 \mathrm{hr}$ & SI & $\begin{array}{l}\text { Puede aplicarse al follaje; no aplique cuando las plantas estén estresadas o la } \\
\text { temperatura del aire sea }>90^{\circ} \mathrm{F} \text {. Si se aplica a plántulas o plantas pequeñas en } \\
\text { macetas, use las dosis descritas para cultivos ornamentales. Leer etiqueta. }\end{array}$ \\
\hline \multicolumn{5}{|c|}{$\begin{array}{l}{ }^{1} \text { Código FRAC (grupo de fungicidas): El número ( } 33 \text { y } 44 \text { ) y las letras (NC) se utilizan para distinguir los grupos de modos de acción de los fungicidas. Todos } \\
\text { los fungicidas dentro del mismo grupo (con el mismo número o letra) indican el mismo ingrediente activo o un modo de acción similar. Esta información } \\
\text { debe tenerse en cuenta para las decisiones de manejo de la resistencia a los fungicidas. Sin embargo, los productos con NC se consideran de bajo riesgo } \\
\text { y no requieren ninguna rotación a menos que se indique específicamente en la etiqueta. NC = no clasificado, incluye aceites minerales, aceites orgánicos, } \\
\text { bicarbonato de potasio y otros materiales de origen biológico. Fuente: FRAC Code List 2019; http://www.frac.info/ (FRAC = Fungicide Resistance Action } \\
\text { Committee). }\end{array}$} \\
\hline
\end{tabular}

